\title{
http://doi.org/10.15359/ree.2004-6.8
}

\section{QUÉ SIGNIFICA LA EDUCACIÓN PÚBLICA}

\author{
Rafael Cuevas Molina'
}

La educación ha estado siempre ligada a los proyectos de desarrollo que se han impulsado en América Latina a través de su historia. En su contexto ha cumplido siempre un papel central. La educación pública ha sido también un canal importante de movilidad social. En nuestros dias, se encuentra ante una encrucijada planteada por el impulso del modelo neoliberal de desarrollo.
Education has always been related to the development projects that have been promoted in Latin America throughout its history. Within this context, education has played a central role as well, public education being an important means for social mobility. Currently, education finds itself in a cross. road derived from the boost of the neoliberal movement for development.

1 Prolesor e investigador del Instituto de Estudios Latinoamericanos de la Universidad Nacional de Costa Rica en donde actualmente es director de la Macstría en Estudios Latinoamericanos. Correo electrónico: rmolina@una.ac.cr 
La educación tiene un papel central en el desarrollo de los pucblos. La cducación pública cs indispensable no sólo para que esc desarrollo se dé, sino también, para que sca equitativo.

Históricamente, en nuestras jóvenes repúblicas latinoamericanas la cducación ayudó, de mancra fundamental, a conformar las identidades nacionales que hoy nos conjuntan. Efectivamentc, desde mediados del siglo XIX, pero cspecialmente en su último tercio, las oligarquias libcralcs se vicron en la neccsidad de impulsar proyectos de lo que el inglés Bencdict Anderson ha dado cn llamar la "invención" de la nación. Sc trata, ni más ni menos, de cstratcgias culturales que "imaginaron" (otro término puesto en circulación por Anderson) un cntorno delimitado (por frontcras) en cl que cxistian patrones de comportamicnto, costumbres y hábitos comunes. A csos hábitos, costumbrcs y comportamientos comunes se les llamó "identidad nacional".

Como es sabido, es totalmente iluso hablar de una sola identidad en tcrritorios tan extensos como los de los estados modernos. Lo característicos es, por el contrario, la variedad, la multiplicidad de identidades basada en la multiculturalidad existente. Por ello, el proyecto de construcción de la nación pasa por inventar e imaginar esa identidad única que supuestamentc atañe a todos. Para esto, debe hacerse una lectura interesada y, necesariamente, parcial, del pasado histórico, seleccionando y resaltando lo que de ese pasado le es conveniente, y opacando y pasando a un segundo plano (o haciendo desapareccr) lo que de ese pasado no conviene a los intereses de quien construye el proyecto. Se trata, por lo tanto, de un proceso de "construcción de la tradición" (en el sentido de Raymond Williams) que da sustento a "la identidad nacional".

Como se puede apreciar por lo antedicho, el nacionalismo se encuentra en la base de la nación y no a la invcrsa. Quiere decirse con esto que no existen (como se pensaba hasta antes de los años 50 del siglo XX) naciones preexistentes al Estado, naciones que encuentran una expresión en la organización cstatal. En América Latina, la organización del Estado antecedió a la construcción de la nación y del nacionalismo. Fue un proceso que encontró su apogeo en las primeras tres décadas después de la independencia, pero que luego debió "amarrarse" con la invención de la nación.

Teniendo al aparato del Estado relativamente consolidado (o en proceso avanźado de consolidación), cl nacionalismo jugó el papel de conjuntador de voluntades en función del proyecto de desartollo dominantc. Pongámoslc nombre a lo anterior: cl proyecto dominante era el de las oligarquías libcralcs, que buscaba la forma de incorporarsc al mercado mundial a través de algún producto agropecuario, que en el caso argentino y uruguayo fue la carnc y el cucro, en el cubano, dominicano y puertorriqueño fue la caña de azúcar, en cl centroamcricano (con excepción de Honduras) fue cl café, etc. 
A ese proceso de construcción de la nación, difundiendo (pero también constıuyendo) el nacionalismo, contribuyeron diversos factores. Mencionaremos algunos de los principales: los medios de comunicación fue uno; la educación (pública) fue otro. Entre los medios de comunicación de la época debe mencionarse a la prensa escrita. El papel que juega la televisión como difusor de modelos culturales que ayudan a construir un imaginario cultural (globalizado) hoy en día, fue el que tuvo la prensa escrita en el proceso de construcción de la nación y del nacionalismo en el siglo XIX. Los periódicos y las revistas ayudaron a imaginar esa comunidad que es muy difícil (si no imposible) conocer de primera mano. La educación pública, por otra parte, se encargó de formar lealta. des patrióticas acordes con el pasado histórico que los intelectuales (positivistas) se habían encargado de identificar como significativo. Ciertamente, no sólo formó las lealtades al proyecto nacionalista de los liberales, el proyecto de afianzamiento de un sistema predominantemente capitalista, sino también creó hábitos, habilidades y costumbres necesarias para el impulso (en todos los ámbitos: productivo, político, social, etc.) del proyecto de "modernización" de la sociedad.

La modemización implicó transformaciones verdaderamente revolucionarias en las sociedades de entonces. Hubo que formar hábitos de higiene (desde los más banales: no se orina en la vía pública, no se escupe en el interior de un teatro, hasta los atinentes a la salud pública: hay que bañarse todos los días para evitar epidemias de piojos, ladillas y gartapatas; hay que cambiarse de ropa interior para evitar infecciones, hay que tener higiene bucal para conservar la dentadura, etc.), hábitos de trabajo (hay que saber que a una fábrica o taller se entra y se sale a una hora exacta, lo que implica saber leer el reloj; hay que saber adaptarse al ritmo de trabajo propio de la producción industrial, distinta de la rural, etc.), habilidades mínimas (contar, sumar, restar y dividir para poder pesar y medir y saber dar un vuelto; escribir o, cuando menos, firmar; leer para poder encontrar el nombre en una lista o en una nómina, etc.).

La educación pública cumplió en muy buena medida la función de "civilizadora" de las masas que debían pasar a formar parte, como fuerza de trabajo, del modelo de desarrollo agroexportador dominante. Fue ahí en donde se consagraron las tradiciones "sagradas" que honran a la Patria: el saludo (a veces diario) a la bandera; el canto del himno nacional; la festividad de las efemérides: alabanza de héroes como dioses; conmemoración de batallas apoteósicas; la celebración del paisaje, de la flora y de la fauna "incomparable" de la Patria, etc.

Creció, por lo tanto, el número de escuelas, y dentro de e!las se distribuyeron las cartillas civicas e históricas que se aprendieron de memoria; apareciero». los materiales didácticos en los que se representaban los linderos de la Patria, sus rios y montañas, y se vieron por primera vez las efigies de los héroes, siempre 
gallardos, siempre viendo al horizonte, siempre transmutados por la alta misión que les habia tocado jugar en la vida.

Hubo, claro está -como la hay ahora- educación para unos y para otros. Para unos, la educación básica, elemental, la necesaria para desempeñarse como trabajador manual. Elemental, es cierto, pero gramisa, lo que significo un paso gigantesco que permitió que grandes contingentes de población tuvieran acceso a un mundo culturalmente más amplio que el que le proporcionaba su contexto familiar o barrial. Para otros la formación que iba más allá, en donde se aprendía el latín y el griego, la naciente literatura nacional, los modales para comportarse en sociedad, etc. Hubo también educación especializada: se formaron maestros (sobre todo maestras) que en algunos países se transformaron en verdaderos promotores culturales de amplio prestigio social. La educación no sólo reprodujo las diferencias sociales sino las marcó aún más: las evidenció y profundizó.

La educación pública fue eslabón central en el impulso del proyecto de desarrollo vigente. La escuela fue el principal centro promotor de la nueva cultura y los maestros y maestras obtuvieron un rango social acorde con ese papel. Esto no fue obice para que en ella misma nacieran y se divulgaran proyectos alternativos al dominante. Desde las escuelas públicas, deśde las escuelas normales, desde los institutos magisteriales, desde las universidades públicas salio un movimiento contestatario y renovador en las primeras décadas del siglo XX. Al calor de los acontecimientos que sacudían al mundo: la Revolución Mexicana de 1910, la Revolución Rusa de 1917, la invención del cinematógrafo y la difusión de la radio, etc., jóvenes educados, maestros $\mathrm{e}$ intelectuales, se aliaron ideológicamente, a veces también políticamente, con obreros y artesanos, y abogaron por una sociedad más justa y equitativa. El nacionalismo alcanzó con ellos nuevos contenidos pues ya no respondieron solamente a los estrechos límites del Estado-nación sino que tuvieron un nuevo referente, esta ver continental: América Latina, la Patria latinoamericana que se encontraba amenazada por un enemigo común: la expansión norteamericana, primero teritorial (sobre México y el Caribe) y, principalmente, económica. Las universidades públicas fueron privilegiados receptáculos de este tipo de ideas y movimientos: la de Córdoba, en Argentina, famosa por su movimiento de 1918; la mexicana, años más tarde, de donde surgieron hombres como Vasconcelos; la de San Marcos, en Lima, a la que se asociaban nombres como los de Mariátegui y Haya de la Torre. La educación pública en la vanguardia, no sólo en la solventación de las necesidades perentorias del proyecto de los sectores dominantes sino, también, como puntal de renovación ideológica y cultural: como visión alerta, como conciencia crítica. 
Mis adclante, en el transcurrir de nucstra historia republicana, la cducación pública ha scguido jugando siempre un papel preponderante y central. Despućs de los años cincuenta, lucgo de la Segunda Guerra Mundial, cuando Centroamérica y cl Caribe pasan a inscribirsc, de mancra mucho más definitiva, en la órbita del dominio nortcamericano, como mecanismo de movilidad social, sobre todo en aquellos países que habían tenido un más o menos exitoso proceso de construcción de su proyecto liberal en el siglo XIX y principios del XX. La cducación, ahora, contribuyendo centralmente a la expansión y consolidación de las capas medias -sobre todo, aunque no exclusivamente, urbanas- que podrian acceder a través suyo, a la casa propia, a cicrtos aparatos clectrodomćsti$\cos$ (cl reirigcrador, la TV en blanco y negro, la cocina a gas o clćctrica) y, a veces, a un apjarato automotor para trasladarse al trabajo en la creciente burocracia cstatal que les acogía y les daba salario seguro a fin de mes, a la empresa o al negocito propio. Para entonces, el modelo de desarrollo apostó, al calor de las propucstas de la CEPAL, por la sustitución de importaciones y, por lo tanto, por la formación y consolidación de una industria nacional que, lógicamente, necesitaba de fucrza de trabajo calificada, de técnicos medios y cuadros dirigentes.

Fuc el período en el cual las universidades públicas crecicron exponencialmentc: en la región centroamericana, la tricentenaria Universidad de San Carlos de Guatemala y la Univessidad de Costa Rica. La primera pasaría de contar con alrededor de 25 mil estudiantes en la década de los 60, a más de 100 mil a principios del siglo XXI. Tambićn conoce un auge importante la celucación vocacional tćcnica, que forma a los técnicos especializados para resolver los múltiples problemas que planteaba la concreción del nuevo modelo de desarrollo.

Es decir, la cducación pública jugando, al igual que en el siglo XIX, un papel primordial en el modelo de desarrollo vigente, pero también cjerciendo su tarca de conciencia crítica. De los institutos de educación media, de las universidades públicas saldrán aquellos que alimentarán los movimicntos cuestionadores del sistema y que, en casos extremos, llegaran a oponćrscle de forma violenta. El estudiante de nivel secundario y universitario pasará a ser sinónimo de rebcldía utópica. De la universidad pública saldrán análisis y propuestas que sus profesores $\mathrm{c}$ investigadores han clucubrado al calor de los nucvos acontecimientos que sacuden al mundo: la Revolución Cubana, el mayo francćs del 68, la matanza de Tlatclolco en Mćxico, cl movimicnto hippie en los Estados Unidos de Amćrica, cl movimiento nacionalista del que empiczal a llamarse Tercer Mundo, la descolonización del África, cl nacimiento del bloque socialista. La teoría de la dependencia se abre paso en los corredores universitarios y mucstra (pero tambićn denuncia, a tono con la ćpoca) que estructuralmente los países latinoamericanos somos deformados de nacimiento, lo que nos ha 
llevado a seguir reproduciendo la dependencia respecto a los paises desarrollados. Hay un pensamiento propio que intenta dar respuestas propias latinoamericanas, tercermundistas.

A partir de la década del ochenta varía el panorama mundial. Hacia mediados de ésta se inicia el impulso de políticas que se han caracterizado como neoliberales, y a finales de la misma se derrumba el campo socialista. Sin mayores obstáculos que se le opongan, el sistema capitalista mundial logra erigir su proyecto como el dominante sin aparente alternativa. Al mercado se le atribuye así carácter central en la dinámica social. El capital, en su afán de reproducirse, llega a los más recónditos rincones del planeta sustentado en ias nuevas tecnologías cibernéticas y telemáticas que permiten realizar transacciones financieras en segundos; el ritmo del desatrollo se acelera haciendo obsoleto lo que hasta hace poco era novedad; el conocimiento pasa a convertirse en capital de primer orden, y su expresión tecnológiciı se transforma en fuerza productiva directa. El avance de la ciencia y la técnica, que se encuentran en la base de la revolución cultural que transforma el mundo a principios del siglo XXI, pone como nunca antes, a la formación y educación del ser humano en el centro de las necesidades. En el contexto de la implementación de las políticas neoliberales, sin embargo, las diferencias existentes entre los paises desarrollados y los eufemísticamente llamados en vías de desarrollo se agrandan, la brecha es cada vez mayor y la educación no escapa a estos condicionantes.

En la educación han penetrado las tendencias dominantes de la época. Se va imponiendo paulatinamente el mercado como criterio de calidad y la concepción según la cual la ofeıta de formación y conocimientos es un servicio que se vende y se compra como mercancía. Por su parte, acorde con la concepción según la cual el Estado no debe intervenir más que como árbitro entre las fuerzas del mercado, éste se retrae de muchas de las que hasta la vispera se consideraba eran sus obligaciones: la seguridad social, el suministro de energía, la vivienda para los sectores medios y bajos de la población, la educación para todos. Como hongos surgen entonces las opciones de educación privada en todos los niveles: en el preescolar, en la primaria, en la secundaria y en la universitaria. La educación se transforma en un espacio disputable en el que se pueden obtener beneficios económicos a costa de las necesidades urgentes que impone la nueva sociedad. A la educación pública, mientras tanto, se le regatean los fondos que otorga el Estado y las condiciones materiales se deterioran; amplios sectores de la población se ven marginados del sistema educativo; por razones economicas, muchachos y muchachas desertan de la educación secundaria y salen a buscar opciones de trabajo que será casi siempre mal pagado y los condenará a reproducir el círculo vicioso de la pobreza; un porcentaje pequeño de los que ingresaron a 
los primeros años de la educación primaria logra llegar a las universidades. Aqui les espera un nuevo obstáculo: en muchas partcs hay que pasar cximenes de admisión que sólo los quc han tcnido acceso a la educación de los privilegiados logran pasar. No solamente cso les espera: ¿puede un hijo de obrero, de campesino, costear los gastos de carteras como Medicina u Odontología, por cjemplo, cn donde hay que comprar instrumental que cstí fucra del alcance de su bolsi110 ? Todo esto mientras se reducen los ya exiguos fondos destinados palia becas que ayuden a aquellos provenientes de los sectores menos pudientes a pagarsc una habitación, a comer aunque sca mediocrementc.

Grandes contingentes de población quedan, entonces, al margen de las posibilidades no sólo de acceder a mejores niveles de vida sino, lambién. de contribuir al desarrollo. Unos pocos no solamente concluirán la cducación universitaria en nucstros paíscs latinoamcricanos sino que podrán partir al cxtranjcro a sacar un posgrado. Y allá se quedarán algunos, buscando las condicioncs óptimas que acá no se les ofrecen.

Asi no vamos a ninguna partc. Las socicdades yue desperdician sus mejorcs recursos dejándolos al garete no pucden sino reproducir las condiciones de dependencia y subdesarrollo en la que sicmpre, en muy bucna partc por estc tipo de políticas miopes, han cstado sumidas. La educición pública, para todos, no cs un privilcgio sino una tabla de salvación. No pucde scr cualquicr cduciación pública:

- Tiene que ser una educación públical de calidad, lo cual significa que este acordc con las necesidades y estándares de la sociedad en la cual ticnc lugar.

- Tiene que ser una cducación pública que forme valores acordes con un ser humano integral, solidario, honesto, trabajador.

- Tíenc que scr una cducación pública en donde se aprenda a comprendemos como scres iguales, pero diversos.

- Ticnc que scr una educiación pública en la que sc ubiquc al ser humano como parte de la naruralezu, con la cual compartimos destino.

- Ticnc que ser una cducación pública orientada hacia las ncccsidadcs del desarrollo sostenible, único que nos permitirá acceder a mcjorcs cotas de calielad de vida.

En las condiciones actuales, en el marco de las tendencias dominantes cn la contcmporaneidad, lo anterior parece mucho pedir. Pucde ser que sea mucho pedir, pero es lo que hay que pedir y cxigir. Solamente la acción organizada de la sociedad civil, la misma quc empieza a esbozarsc en espacios como el Foro Social Mundial y' su Foro Mundial de Educación, puede inclinar la balanza cn otra dirección. Sólo la acción concertada de las fuerzas intcresadas cn otro mundo 
posible pucde impulsar los cambios sociales, políticos, cconómicos y cullurales necesarios para que la educación pase a jugarcl papel que le corresponde en nucstras ticiras latinoamericanas: un papel central, en cl que el ser humano -lodo ser humano- pueda construirse como centro resplandeciente del desarrollo.

Eso debe significar la educación pública. 